Chapman University

Chapman University Digital Commons

Education Faculty Articles and Research

Attallah College of Educational Studies

$1-28-2019$

\title{
Schoolwide Positive Behavioral Interventions and Supports in an Alternative Education Setting: Examining the Risk and Protective Factors of Responders and Non-Responders
}

Amy-Jane Griffiths

Chapman University, agriffit@chapman.edu

Jared T. Izumi

University of Missouri

James Alsip

Green Dot Public Schools

Michael Furlong

University of California, Santa Barbara

Gale M. Morrison

University of California, Santa Barbara

Follow this and additional works at: https://digitalcommons.chapman.edu/education_articles

Part of the Educational Assessment, Evaluation, and Research Commons, Educational

Leadership Commons, Educational Psychology Commons, Other Education Commons, and the Social and Philosophical Foundations of Education Commons

\section{Recommended Citation}

Griffiths, A.-J., Izumi, J. T., Alsip, J., Furlong, M. J., \& Morrison, G. M. (2019). Schoolwide positive behavioral interventions and supports in an alternative education setting: Examining the risk and protective factors of responders and non-responders. Preventing School Failure: Alternative Education for Children and Youth, 63(2), 149-161. doi: 10.1080/1045988X.2018.1534224 


\section{Schoolwide Positive Behavioral Interventions and Supports in an Alternative Education Setting: Examining the Risk and Protective Factors of Responders and Non-Responders}

\section{Comments}

This is an Accepted Manuscript of an article published in Preventing School Failure: Alternative Education for Children and Youth, volume 63, issue 2, in 2019, available online at DOI: 10.1080/1045988X.2018.1534224. It may differ slightly from the final version of record.

\section{Copyright}

Taylor \& Francis 


\title{
Running Head: SW-PBIS IN ALTERNATIVE EDUCATION
}

School-Wide Positive Behavioral Interventions and Supports in the Alternative Education Setting: Examining the Risk and Protective Factors of Responders and Non-Responders

\author{
Amy-Jane Griffiths
}

Address correspondence to Amy-Jane Griffiths, College of Educational Studies, Chapman

University, One University Drive, Orange, CA 92866; agriffit@,chapman.edu (email)

Jared T. Izumi

Address correspondence to Jared T. Izumi, Department of Educational, School, and Counseling Psychology, University of Missouri, 16 Hill Hall, Columbia, MO 65211;

jaredizumi@,mail.missouri.edu (email)

James Alsip

Address correspondence to James Alsip, Green Dot Public Schools, 1149 S Hill St, Los Angeles,

CA 90015; james.alsip@greendot.org (email)

Michael Furlong 93106, USA; mfurlong@ucsb.edu (e-mail).

Gale M. Morrison

Address correspondence to senior author, Dr. Amy Jane Griffiths. 


\begin{abstract}
This research examined the risk and protective factors of responders and non-responders to a school-wide implementation of positive behavioral interventions and supports (SW-PBIS) within an alternative school. Students completed self-perception measures of individual, school, community, and home systems. Multivariate analysis of variance indicated a statistically significant difference between responders and non-responders on the individual and school systems models. Direct logistic regression indicated that within these models, hostility, destructive expression of anger, depression, academic self-concept, attitude to teachers, and attitude to school each made a significant contribution in identifying responders and nonresponders. Findings suggest that factors at the individual and school levels may be crucial in identifying individuals who respond to SW-PBIS. Interventions that target specific risk factors may improve responsiveness to SW-PBIS in alternative schools.
\end{abstract}

Keywords: alternative schools; at-risk youth; juvenile delinquents; protective factors; risk factors; school-wide positive behavior support 
Student misbehavior is one of the most frequently cited problems occurring in today's public schools. According to the results of the $48^{\text {th }}$ Annual Phi Delta Kappa Poll of the Public's Attitudes Toward the Schools, "a lack of discipline" is the second largest problem in public schools today (Rose \& Gallup, 2016). Despite increased pressure on teachers to ensure academic success through high-quality instruction, many do not receive appropriate training in behavior management and, thus, encounter three times as many behavioral disruptions in their classroom as teachers with effective behavior management strategies (Freeman, Simonsen, Briere, \& MacSuga-Gage, 2013; Stronge, Ward, \& Grant, 2011). Child misbehavior and resulting discipline problems are likely one of the key contributors to nearly $50 \%$ of beginning public school teachers leaving the field within their first five years (DeAngelis \& Presley, 2011) and an increasing number of students being placed in alternative school settings (Snyder, de Brey, \& Dillow, 2016).

Research indicates that, largely due to discipline problems, approximately half of all classroom time is taken up with activities other than instruction (Sugai, Sprague, Horner, \& Walker, 2000). Student misbehaviors, including high levels of noncompliant behavior and inappropriate peer interaction, are directly linked to low academic performance and higher rates of exclusionary discipline such as suspension and expulsion (Michail, 2011). Because many early-career teachers do not receive adequate training in behavior management, many of these students become excluded through suspension and expulsion practices rather than being kept in the classroom and taught appropriate behaviors in the classroom.

To meet the educational needs of all students, school districts often rely on alternative educational programs as a non-traditional placement for students with disruptive and maladaptive behavioral problems. Alternative programs provide more intensive support for 
students whose behavior results in lower attendance rates and fewer earned credits (Lehr et al., 2009; Wilkerson, Afacan, Perzigian, Justin, \& Lequia, 2016).

Since the early 1990s, there has been an increase in the number of alternative education programs, as the number of students in such programs has increased from approximately 130,000 in 1990 to almost 550,000 in 2014 (Snyder et al., 2016). Although it is thought that removing students from the typical school setting and placing them in a more restrictive environment is necessary for their success, a meta-analysis of 57 alternative education program evaluations by Cox, Davidson, and Bynum (1995) found that alternative settings produce limited positive effects. Further, many practices and intervention within the alternative school setting are not considered evidence-based in improving academic skills and behavioral concerns (Schwab, Johnson, Ansley, Houchins, \& Varjas, 2016). To support the needs of all students, it is essential that alternative schools implement appropriate, research-based supports to address both academic and behavioral problems.

In the traditional school setting, there has been a shift toward the use of universal interventions that address the needs of allstudents (Chitiyo, May, \& Chitiyo, 2012). One of the most widely used of these interventions is school-wide positive behavior interventions and supports (SW-PBIS; Positive Behavioral Interventions \& Supports, n.d.). Adopted by more than 20,000 schools across all 50 states, SW-PBIS is a framework that focuses on replacing problem behaviors with prosocial skills in a safe and supportive environment (Bambara \& Kern, 2005). Specifically, SW-PBIS is intended to enhance school climate and decrease challenging, disruptive, and aggressive behaviors while also helping students to reach their full academic and behavioral potential. 
With a whole-school approach, the SW-PBIS framework seeks to define student expectations positively (Burke, Davis, Hagan-Burke, Lee, \& Fogarty, 2014), teach these identified expectations to all students and staff directly (Sugai, Hagan-Burke, \& Lewis-Palmer, 2004), maintain a system that acknowledges and rewards students who meet expectations, and establish a continuum of consequences (Sugai \& Horner, 2009). In addition, SW-PBIS implementation requires the use of data to determine the effectiveness of interventions and for decision-making purposes (Kincaid et al., 2016). Implementation of SW-PBIS can help to transform a school environment from a punitive one to a positive and supportive one.

Research across settings indicates that SW-PBIS can be an effective framework for improving school climate (Bosworth \& Judkins, 2014), student academic achievement (Freeman et al., 2013), and teacher well-being (Ross, Romer, \& Horner, 2012). SW-PBIS can help to reduce both the frequency of disruptive and problematic behaviors, as well as the disciplinary consequences for students who continue to show disruptive behaviors (Childs, Kincaid, George, \& Gage, 2016; Horner et al., 2009; Solomon, Klein, Hintze, Cressey, \& Peller, 2012). SW-PBIS is used across all levels of education, from elementary to high school, and in diverse settings, including rural and urban schools (Bohanon et al., 2006; Childs et al., 2016). Despite the vast amount of research on SW-PBIS, there continues to be a gap in the research in regard to the application of SW-PBIS in the alternative education setting.

\section{SW-PBIS in Alternative Schools}

Although there is limited research on SW-PBIS in the alternative school setting, research conducted in various settings, including urban schools (Childs et al., 2016), juvenile justice programs (Jolivette, Scheuermann, \& Parks Ennis, 2015; Sprague et al.,, 2012), and residential treatment facilities (Swoszoski, McDaniel, Jolivette, \& Melius, 2013), implies that SW-PBIS can 
be used successfully in the alternative school setting at the Tier 1 level (Simonsen \& Sugai, 2013). Under the three-tiered model, or multi-tiered system of supports (MTSS), Tier 1 interventions target the entire school population, whereas Tier 2 and Tier 3 interventions are more targeted and individualized for students who do not respond to Tier 1 interventions alone. Because students in the alternative school setting typically display higher levels of social-emotional and behavioral problems, SW-PBIS can provide the foundation at the Tier 1 level, while more intensive interventions can be used at the Tier 2 and Tier 3 levels (Gagnon, Rockwell, \& Scott, 2008). Regardless of setting, the main features of SW-PBIS, such as clearly posted and positively worded expectations, reinforcement for students who meet expectations, and data-based decision making, can be implemented effectively for all students (Jolivette, McDaniels, Sprague, Swain-Bradway, \& Ennis, 2012; Simonsen, Jeffrey-Pearsall, Sugai, \& McCurdy, 2011).

In a case study of SW-PBIS in the alternative school setting, researchers have found an overall decrease in the frequency of serious incidents that require manual restraint (Simonson, Britton, \& Young, 2010). In the final year of the study's implementation, only $17 \%$ of students had an incident that involved physical aggression, down from 35\% during the previous year. In a similar study that considered SW-PBIS in a K-12 clinical day school, researchers saw a decrease in the number of physical restraints and the use of seclusions (Gelbar, Jaffery, Stein, \& Cymbala, 2015). In terms of individual behaviors, researchers found a decrease in both problem behaviors and office discipline referrals (ODRs) and an increase in positive behaviors over the course of SW-PBIS implementation in an alternative setting (Farkas et al.,, 2012). Although limited, preliminary research indicates that the SW-PBIS framework can be used at the universal level in the alternative school setting. 


\section{Responders and Protective Factors}

One important factor when considering the effectiveness of SW-PBIS is that of responders versus non-responders. Responders are those who respond to SW-PBIS interventions, as recorded by the number of rewards earned throughout the process, whereas non-responders do not participate in the intervention and thus do not earn as many rewards throughout the year. In addition, responders experience a decrease in discipline incidents, whereas non-responders have little to no change in the number of discipline logs before and after SW-PBIS implementation.

One theoretical framework that can be used to understand responders and non-responders to SW-PBIS is that of risk and protective factors, which affect the ability of children to adjust well to significantly challenging circumstances (Theron, Liebenberg, \& Malindi, 2013).

Research indicates that resilience is a transactional process between an individual and his or her environment (Sameroff \& Mackenzie, 2003). Therefore, the presence of individual risk and protective factors, in addition to various systems (e.g., families, schools, peers, communities) may be an indicator of responsiveness to SW-PBIS. For those with strong internal protective factors but a poor perception of systems, SW-PBIS may provide the means to increase overall resilience.

\section{Risk and Protective Factors}

Risk factors, including biological, behavioral, environmental, and sociocultural characteristics, are those that increase the probability of negative outcomes, whereas protective factors are those that decrease the probability of negative outcomes (Loeber, Farrington, Stouthamer-Loeber, \& White, 2008; Ungar, 2011). Inherent in the notion of risk and protective factors is the interplay between individual characteristics and environmental circumstances (Kassis, Artz, \& White, 2017). Outcomes in a child's life are directly related to the interaction 
between the individual and his or her experiences. To fully understand the risk and protective factors of youth, it is important to consider their experiences in multiple contexts across time.

An individual's traits, experiences, and outcomes may be conceptualized into individual, family, peer, and community systems (Foorman, York, Santi, \& Francis, 2008; Loeber et al., 2008). When risk factors within any of these systems remains unaddressed, children may develop negative traits and an increase in negative experiences and outcomes. For many students in the alternative school setting, risk factors may exist across several of these systems. To understand response to SW-PBIS, it is important to acknowledge this interplay between individual, family, peer, and community risk and protective factors.

Various characteristics in the individual system have been associated with student misbehavior, including impulsivity, poor coping, depression, drug use, and grade retention, as well as low academic achievement, future aspirations, and school connectedness (Sander \& Sharkey, 2007; Stormshak \& Dishion, 2002). Within the individual system, there can also be several protective factors also exist, such as high intelligence; internal locus of control; faith; optimistic sense of future; and high self-esteem, self-concept, and self-efficacy, which can act to decrease the probability of negative outcomes (Donnellan, Trzesniewski, Robins, Moffitt, \& Caspi, 2005; Greenwald et al., 2002; Kolaitis et al., 2014).

Risk and protective factors also exist in an individual's environment. Familial (e.g., inconsistent or harsh discipline, family conflict, lack of basic needs), school (e.g., exclusionary discipline, tracking, retention), community (e.g., poverty, discrimination, crime), and peer (e.g., gang membership) factors can all have a negative impact on a child's outcomes and responses to negative events (Sander \& Sharkey, 2007; Stormshak \& Dishion, 2002). However, protective factors in each ecological context, including family systems (e.g., authoritative parenting with 
high expectations and warmth), school systems (e.g., school bonding and family involvement), community systems (e.g., connectedness to groups and organizations), and peer systems (e.g., quality peer relationships) may serve to counteract various risk factors in an individual's life (Lam \& McBride-Chang, 2007; Leadbeater \& Way, 2007).

\section{The Current Study}

Although research supports the use of SW-PBIS in traditional schools across all grade levels and settings (e.g., rural, suburban, urban), there is limited research on responders and nonresponders to SW-PBIS in the alternative school setting, particularly in regard to responders and non-responders. In an effort to begin to address this gap in the literature, the present study focused on risk and protective factors of students in alternative education and how these factors, across multiple ecological contexts, relate to student response to SW-PBIS. Given the significant differences between alternative school settings, student population characteristics, services provided, behavior management strategies used, and general environmental factors within the alternative school, understanding the characteristics of responders and non-responders to SWPBIS is important to identifying specific SW-PBIS implementation strategies. Therefore, the purpose of the current study is to determine which students respond best to SW-PBIS in the alternative school setting.

Within the context of risk and protective factors, it is hypothesized that students who participate in and respond to SW-PBIS interventions are more likely to report higher levels of internal protective factors (hope, life satisfaction, academic self-concept, interpersonal relations, community caring, and relations with parents) and lower levels of risk factors (hostility, destructive expression of anger, depression, sense of inadequacy, family conflict, social stress, norms for aggression, attitude to school and attitude to teachers measures) than the participating 
but non-responding students. Because each system (individual, school, social/community, and family) includes a combination of risk and protective factors, it is thought that student perceptions of each of system also will have an impact on their response to intervention.

The present study involved a one-year evaluation designed to examine the implementation of SW-PBIS Tier 1 supports in the alternative high school setting. Study findings will be used to examine how student perceptions of individual, school, community, and family systems impact their response to SW-PBIS and answer the following questions:

1. To what extent is there a difference between groups (responders and non-responders) in risk and protective factors across various ecological systems (individual, school, community/social, and home)?

2. Given student functioning at Time 1 (pretest), what are the best predictors of who will participate in and respond to SW-PBIS interventions?

\section{Method}

\section{Setting and Participants}

Study participants were enrolled in a community school on the central coast of California. Students ranged from those in grades 7 through 12, and many had been previously involved in the juvenile justice system. The school's student population consisted of 99\% Latinx students, with $98 \%$ as meeting the criteria for free or reduced-cost lunch. Many of the students were affiliates or members of local gangs and had been exposed to trauma. The school included students who were expelled from their home school, had experienced externalizing and/or internalizing disorders, and had significant truancy problems. Because there is typically high mobility within the alternative school population, many students were enrolled at the school for only a short period of time. Consequently, it was important to identify which students among the 
potential study participants had been exposed to the SW-PBIS interventions for a sufficient amount of time to respond to the interventions. Only students who had been exposed to SWPBIS interventions for at least 100 school days (approximately five months) and met the criteria as either a responder or non-responder (the criteria are described in data analysis plan section) were included as study participants. Although 90 students were enrolled for 100 school days or more, only 42 students met the criteria as responders or non-responders. The selected sample of 42 students consisted of 22 responders and 20 non-responders, of whom $62 \%$ were male and $38 \%$ were female. In addition, participants ranged in age from 12 to 17 years old, and $76 \%$ of participants were considered English Language Learners (ELL). One student included in the study was receiving special education services through the Resource Specialist Program, while the others were considered to be students in general education.

There were five classrooms at the study school site, with each having one core teacher (T1, T2, T3, T4, and T5) and two teacher assistants (T1 TA1, T1 TA2, etc.). The core teachers include four males and one female teacher, ranging in age from 24 to 40 years old. Two of the teachers had less than five years of teaching experience (T2 and T3), one teacher had between five and ten years of experience (T1), and two teachers (T4 and T5) had more than ten years of teaching experience at the time of the study.

\section{Design}

Data were gathered using a combination of methods, including survey, observation, and review of permanent products. A pre-post (AB) design was used to compare the effects of the intervention between baseline and post-intervention.

\section{Procedures}


Phase I. Before implementation of the SW-PBIS interventions, meetings with the school psychologist, the principal, key county representatives, and university faculty were conducted to discuss implementation details. Staff training and collaboration meetings were conducted weekly during the month before implementation so as to provide an overview of SW-PBIS and to present the importance of using positive reinforcement with the selected population. The schoolwide project was discussed, and teaching staff were asked to work on developing a customized system of SW-PBIS for their school. In the meetings, teachers, teachers' assistants, and the principal were encouraged to work collaboratively in establishing school-wide guidelines to be focused on throughout the year of SW-PBIS implementation. Due to the size of the school, most students were involved in the process of developing the expectations, lesson plans, and rewards. Teachers and research team members engaged each class in a group discussion regarding the behaviors that they would like to see, how the team could effectively develop the associated lessons, and the types of rewards that they would like to earn.

In addition, a smaller group of students were nominated and selected by teachers to lead some of the SW-PBIS efforts from the student perspective. The student leadership team met with the research team monthly to provide feedback and to help plan future lessons and reward programs. Following the collaboration meetings, teaching staff were trained by the principal investigator and school psychologist on SW-PBIS intervention implementation specifics (e.g., teaching expectations, practicing expectations, rewarding students who met expectations). The SW-PBIS focus was maintained throughout the year through regular monthly trainings provided by the researchers and the school psychologist during staff meetings.

Following the meetings and trainings, teachers co-created scripted lesson plans. The scripted lessons were designed to teach explicitly the behavioral expectations to all students and 
to provide examples of what each behavior should look like. School staff also decided to give out acknowledgements (i.e., golden tickets) as a positive reinforcement system (e.g., "I appreciate you for...[teacher fills in specific example]"). Students could earn tickets when they displayed behaviors in alignment with the school-wide guidelines, and they subsequently could enter their tickets into a drawing box.

Phase II. At the principal's request, school staff continued to maintain the existing school-wide discipline strategies during the intervention phase of SW-PBIS. Under the existing system, students were first provided with one warning and then given a check when they broke a classroom rule. If a student received three checks, he or she would receive an afterschool detention.

For SW-PBIS implementation, scripted lessons that reflected the agreed-upon guidelines were created and taught to students by the classroom teacher. The lessons took approximately 45 minutes and were taught at the beginning of the first semester, and the beginning of the second semester. During the lessons, students defined each guideline and provided examples (and nonexamples) of each guidelines. Students also were responsible for creating posters and artwork that represented each guideline. Posters were placed around the school to ensure that guidelines were well known and accessible to all students. Students also were provided with monthly "refresher lessons" that reviewed specific guidelines and required student engagement in related activities.

Students' prize preferences were surveyed on a monthly basis as a means to include students' opinions in the development of the school-wide reinforcement system, and to ensure that students would actually be positively reinforced when earning a prize. According to the reinforcement system, students entered the tickets that they earned into a weekly drawing for 
prizes. At lunchtime on Fridays, one of the teachers would draw two names per homeroom class and read how the student earned the ticket. The winning students were then able to pick a prize from the "mystery motivator box." During the weekly drawings, staff recorded the number of acknowledgement tickets per student to help determine which students were responding to SWPBIS intervention. Acknowledgements were graphed and organized by each classroom team (teachers and staff). Graphed performance feedback was provided on a weekly basis to encourage teamwork within the classrooms and to motivate staff members to continue intervention implementation. Teachers and teacher assistants who gave out the most acknowledgements throughout the week received a certificate and prizes (based on their surveyed interests).

\section{Measures}

The measures used in this study were associated with both implementation process (treatment integrity) and outcomes. The process measures included the School-wide Evaluation Tool (SET; Sugai, Lewis-Palmer, Todd, \& Horner, 2001)), the Effective Behavior Support (EBS; Sugai, Horner, \& Todd, 2000) survey, the number of acknowledgements (golden tickets) given, and observed teacher-student interactions. Outcome measures included incident reports and teacher ratings of student behavior.

School-wide Evaluation Tool (SET). The SET (Sugai et al., 2001) is an instrument used specifically to measure the critical features of PBIS implementation. Horner et al. (2004) reported that the SET can be used to assess: (a) PBIS features in place, (b) annual goals, (c) ongoing efforts, (d) design and revision procedures, and (e) year-to-year progress. Information is gathered through multiple sources including a review of school records, direct observations, and staff and student interviews. In the present study, the SET was conducted by the principal 
investigator before full implementation and following the first year of implementation to determine intervention integrity and critical elements before and after one year of implementation.

Effective Behavior Support Survey (EBS Survey). The EBS Survey (Sugai et al, 2000) was designed to determine the level of implementation and to identify the change priority across four PBIS domains: (a) school-wide, (b) classroom, (c) non-classroom, and (d) individual supports. Completed by the entire staff, the EBS Survey is used during initial stages of training and planning (Sugai et al., 2000). The EBS was completed by teaching and counseling staff before implementation and following the first year of implementation. It was completed by teaching and counseling staff.

Acknowledgements. The number of individual student acknowledgements (golden tickets) was collected by the principal investigator weekly. The number of tickets given to students is a broad and reliable indicator of the degree of participation in the school-wide intervention by both teachers and students (Lassen, Steele, \& Sailor, 2006).

Incident reports. One of the most widely used outcome measures to determine effectiveness of SW-PBIS are ODRs. Empirical evidence supports ODRs as a sensitive indicator of the effects of interventions designed to change student behavior and to improve school climate (Irvin, Tobin, Sprague, Sugai, \& Vincent, 2004). The alternative school in the current study used written incident reports to record school rule violations. Data from the year before SW-PBIS implementation (Year A) served as a baseline. Data from the implementation year (Year B) were used to compare school-wide outcomes. Due to the transient nature of the population, ODR data were not used for individual student comparisons.

\section{Student Characteristics Measures}


All students completed several self-report measures to determine their personal perceptions of their environments and related personal systems. Because each student has a unique set of personal characteristics that interact with the their environment, it is important to analyze specific interactions. Therefore, students completed questionnaires in regard to individual systems, school systems, home systems, and community/social systems before the teacher orientation and SW-PBIS implementation.

Individual system measures. Individual-level characteristics were examined to identify students' perceptions of their internal experiences as they relate to the world. To assess risk factors, the following instruments were used: Multidimensional School Anger InventoryRevised (MSAI; hostility and destructive expression of anger scales; Boman, Curtis, Furlong, \& Smith, 2006; Furlong et al., 2013) and Behavior Assessment Scale for Children-II Self Report of Personality-Adolescent (BASC-2 SRP-A; depression and sense of inadequacy subscales; Reynolds \& Kamphaus, 2004). The MSAI was used to measure the intensity of angry feelings in response to school situations, levels of hostility experienced in schools, and students' positive and negative expressions of anger. Cronbach's alpha for the MSAI for this study was .85 . The BASC-2 was used to measure students' internalizing symptoms related to depression.

To assess protective and resilience factors, the Children's Hope Scale (CHS; Snyder et al., 1997), a six-item scale with three pathway items (e.g., "When I am having a problem, I can come up with lots of ways to solve it") and three agency items (e.g., "I think I am doing pretty well”) was used. Cronbach's alpha value for the total CHS score in this study was .83. Life satisfaction was measured with the Satisfaction with Life Scale (SWL; Diener, Emmons, Larsen, \& Griffin, 1985), for which the Cronbach's alpha value was .80. 
School system measures. School-level characteristics were examined to identify students' perceptions of school and their own academic abilities. The BASC-2 Attitude to School and Attitude to Teachers subtests were used to assess student risk factors and perceptions of school and teachers. Student protective factors were measured using the General Academic Factors of the Self-Description Questionnaire (SDQ). The items of the SDQ are phrased as simple declarative sentences (e.g., "I enjoy doing work in all school subjects") that students rate. Data indicate high consistency for this sample (Cronbach's alpha $=.85)$.

Home system measures. Home level characteristics were examined to identify students' perceived relationships with their parents and their perception of conflict at home. Risk factors associated with the home system were measured using the Family Conflict Inventory (Kurdek, Fine, \& Sinclair, 1995). Family climate was divided into four dimensions: supervision, acceptance, autonomy granting, and conflict. Cronbach's alpha for this scale in the present study is .88. In addition, the BASC-2 Relations with Parents scale was used to assess protective factors associated with the home system.

Community/social system measures. Community- or social-level characteristics were examined by looking at the students' perceived relationships and their supports outside of school and home. The General Belief Questions scale the degree to which students act out verbally and physically when angry. Cronbach's alpha for this scale in the present study was .88 . In addition, the BASC-2 Social Stress subtest was used in order to evaluate the students' perceptions of pressure and tension.

The BASC-2 Interpersonal Relations subtest and a community caring measure were used to assess protective factors. The BASC-2 Interpersonal Relations subtest measures an individual's perception of being liked and respected by peers. To measure the student's 
perception of community caring, a scale from the California Healthy Kids Survey

(www.wested.org/hks; Hanson \& Kim, 2007) was used. The community-based external assets scale used in this study contains six items (e.g., "Outside of my home and school, there is an adult who really cares about me," or "Outside of my home and school, there is an adult who believes I will be a success"). Cronbach's alpha for this scale in the present study was .93.

\section{Data Analysis Plan}

Student participation in the SW-PBIS intervention was measured through the number of earned tickets, the number of tickets turned in, and the number of behavior incidents during implementation. It is assumed that those who participated in the intervention (responders) would have a higher number of tickets and a lower number of incidents ("responders"), while those who did not participate (non-responders) would not earn as many tickets, would not turn in tickets when earned, and would have more incident reports ("non-responders").

Responders were identified by taking the top $25 \%$ of ticket earners (greater than 0.14 per day in Year B) with the fewest number of incidents (less than 0.03 incidents per day). Nonresponders were identified as those with the fewest number of tickets earned (less than 0.14 per day) and the greatest number of incidents (greater than 0.03 per day). A third group ("combinedtype") also emerged and included students in the top 25\% of ticket earners as well as the top $25 \%$ of incident report earners. The combined-type group was not included in the following analyses but should be addressed in future research. A one-way between-groups multivariate analysis of variance (MANOVA) was performed to explore the difference between groups (responders and non-responders) on individual, school, community/social, and home variables. Binary logistic regression was conducted with variables that were significantly different between responders and non-responders to predict responsiveness to SW-PBIS. 


\section{Results}

\section{Research Question 1}

To what extent is there a difference between groups (responders and non-responders) in risk and protective factors across various ecological systems (individual, school, community/social, and home)? Results from the MANOVA are presented under each system category.

Individual system. MANOVA was performed to explore the difference between groups (responders and non-responders) on hostility, destructive expression of anger, hope, life satisfaction, and BASC-2 Depression and Sense of Inadequacy (Table 1). Based on the analysis, there was a statistically significant difference between responders and non-responders on the combined variables, $F(1,38)=3.28, p=.012 ;$ Wilks' Lamda $=.63$; partial eta squared $=.374$. Specific variables also were considered individually. Analysis yielded statistically significant univariate differences in the areas of hostility, $F(1,38)=8.38, p=.006$, partial eta squared $=$ .181 ; destructive expression of anger, $F(1,38)=10.13 p=.002$, partial eta squared $=.374$; and depression, $F(1,38)=9.25 p=.004$, partial eta squared $=.196$. Further analysis of the mean scores also indicated increased scores on all variables for non-responders.

School system. MANOVA was used to determine differences between groups in the areas of Academic Self-Concept on the BASC-2, Attitude to School on the BASC-2, and Attitude to Teachers on the BASC-2 (see Table 1). There was an overall statistically significant difference between responders and non-responders on the combined variables, $F(1,38)=3.20, p$ $=.035$; Wilks' Lamda $=.794$; partial eta squared $=.206$, as well as between specific variables. Analysis revealed statistical significance in the areas of academic self-concept, $F(1,38)=6.38, p$ $=.016$, partial eta squared $=.141 ;$ attitude to teachers, $F(1,38)=7.51, p=.009$, partial eta 
squared $=.161$; and attitude to school, $F(1,38)=6.36, p=.016$, partial eta squared $=.140$. Mean scores also indicated higher scores on the attitude to teachers and attitude to school for nonresponders, while responders had higher mean scores on academic self-concept.

Home system. Based on the MANOVA, there was no statistically significant difference between responders and non-responders on the combined variables $(F(1,38)=1.94, p=.157$, Wilks' Lamda $=.907$, partial eta squared $=.093$ ) for home systems.

Community/social system. Based on the MANOVA, there was no statistically significant difference between responders and non-responders on the combined variables $(F(1$, $38)=2.22, p=.086$, Wilks' Lamda $=.797$, partial eta squared $=.203$ ) for community caring, norms for aggression, or interpersonal and social stress on the BASC-2 (Table 1).

\section{Research Question 2}

Given student functioning at Time 1 (pretest), what are the best predictors of who will participate in and respond to SW-PBIS interventions? Direct logistic regression was performed to assess the impact of the significant variables from the MANOVA on the likelihood that respondents would meet the criteria for the responder or non-responder groups. The model contained six variables from the various systems (hostility, destructive expression of anger, depression, academic self-concept, attitude to school, and attitude to teachers). The full model, which contained all predictors, was statistically significant $\left(\chi^{2}(6, N=40)=12.58, p<.05\right)$, indicating that the model distinguished between responders and non-responders. The model explained between 27\% (Cox and Snell $R^{2}$ ) and 36\% (Nagelkerke $R^{2}$ ) of the variance in responder status and correctly classified $70 \%$ of the cases. None of the independent variables included in this particular analysis made a unique, statistically significant contribution to the model. 


\section{Treatment Implementation Integrity}

The total mean score for the SET was examined in Year A (baseline) and Year B (implementation year). The results indicate that the percentage of critical components implemented in the school increased from $18 \%$ to $69 \%$ and that increases occurred in all categories except "system for responding to behavioral violations" and "district level support." Four scores fell under the $80 \%$ level of implementation ("system for responding to behavioral violations," "district level support," "monitoring and evaluation," and the total mean score). The total mean score was negatively affected by the "district level support" section of the SET (see Figure 1). The alternative school was not supported by the local school districts but rather was a program of the county education office and functioned relatively independently with regard to leadership and spending decisions; therefore, the questions related to district support were not applicable within this system structure. If the district level support component is removed from the average, the total mean score is at $79 \%$ of implementation.

The EBS survey was used as a measure of staff perception of SW-PBIS during Year A (when SW-PBIS was not present) and Year B (when SW-PBIS was present). The current study focused primarily on the school-wide level of intervention. Therefore, a test for significance was conducted solely for the school-wide component of the survey. A $z$-test was conducted to compare the proportion of responses that were "in place," "partially in place," and "not in place" for school-wide intervention from Year A to Year B. The results indicated there was a significant change in the proportion of teachers who rated school-wide components being "in place" between Year A and Year B of the study (one-tailed $z$-test; $z=5.45, p<.05$ ). Thirty percent of the ratings in Year A described school-wide components as being “in place," compared to 59\% in Year B. 


\section{Discussion}

Although a substantial body of research supports the use of SW-PBIS in elementary schools and secondary schools, few studies have evaluated the impact of SW-PBIS in alternative education settings (Farkas et al., 2012; Gelbar et al., 2015; Simonson et al., 2010), with no studies conducted on risk and protective factors as predictors of response to SW-PBIS (Solomon et al., 2012). The current study was conducted to answer two main questions: (a) To what extent is there a difference between groups (responders and non-responders) in the areas of individual systems, school systems, community/social systems, and home systems? and (b) Given student functioning at Time 1 (pretest), what are the best predictors of who will participate in and respond to SW-PBIS interventions? The results from the present study provide some insight into students in alternative education and their participation in SW-PBIS.

\section{Research Question 1}

The analysis indicates that the individual systems model and the school systems model are each able to distinguish between responders and non-responders. Several measures were used to examine risk and protective factors, and significant differences were evident only for the risk factor measures only. This is likely because many of the students who were enrolled in an alternative school setting do not possess a wide range of experiences with protective factors. Therefore, there was a larger impact of risk factors than protective factors in response to SWPBIS.

Within the individual systems model, hostility, destructive expression of anger, and depression made unique, significant contributions to the model. It is likely that those who do not have high self-perception and use anger and hostility to navigate the world are less likely to respond to positive reinforcement. If a student tends to view the world as hostile, he or she may 
not trust adults who engage with them in more positive interactions. Instead, he or she may view positive interactions as manipulative and insincere. For example, one of the non-responder students told his teachers that the golden tickets were just another way that the school was trying to control the students. For alternative schools, it may be necessary to include interventions across all three tiers of MTSS, such as anger management, that help students develop personal protective factors that counteract hostility, destructive expression of anger, and depression.

Within the school systems model, academic self-concept, attitude to teachers, and attitude to school each made a significant contributions to the model. It is expected that school level student perceptions would predict who responded to a school-wide intervention, as students with higher perceptions of school are more likely to be engaged in school programs. Similarly, students with higher academic self-concept were more likely to participate in the intervention, whereas students with a more negative view of their teachers and of the school before intervention were less likely to participate. Because SW-PBIS generally takes three to five years for full implementation, it is likely that changing the school environment to one that focuses on rewarding positive behaviors rather than punishing misbehaviors would increase perceptions of school-level systems (Bohanon et al., 2006; Harms, 2010). However, additional research regarding student perceptions before and after implementation of SW-PBIS Tier 1 supports is needed to determine their effect on student perceptions of systems.

\section{Research Question 2}

In addition to MANOVA, logistic regression revealed that hostility, destructive expression of anger, depression, academic self-concept, attitude to school, and attitude to teachers, as a group, predicted responders and non-responders. As discussed previously, the two constructs appear to be related to how the student views himself or herself and his or her views 
of teachers and schools. Because the variables were significant only at the group level rather than at the individual level, it is not possible to make assumptions about which individual variables would predict group membership. When reviewing the mean differences, however, responders had higher academic self-concept (protective factors) in comparison to non-responders. Further, non-responders had higher scores on hostility, destructive expression of anger, depression, attitude to teachers and attitude to school (risk factors).

For students who were considered non-responders to SW-PBIS, the study provides a preliminary step toward developing an understanding of what forms of support these students may require. For those who did not respond to Tier 1 supports alone, it is possible that coordinated intensive Tier 2 and Tier 3 interventions may have elicited greater response. It is essential that educators be mindful of the types of youth who may not respond at the early stages of intervention as to avoid the "wait to fail model." If "non-responding" youth do not receive appropriate intervention as early as possible for their extreme behaviors, severe negative consequences (e.g., getting arrested) may result. For this reason, more individualized interventions, such as Check In/Check Out (CICO) and individualized behavior support plans, may be necessary for students who exhibit increased risk factors. By attending to students' individual differences and providing a continuum of supports, it is easier for schools to provide appropriate, effective interventions in an efficient manner regardless of students' level of need.

\section{Practical Implications}

It is important to consider the population within the alternative school setting from an ecological perspective. Often, students in the alternative setting have significantly higher psychological concerns in addition to a higher incidence of conduct and behavioral problems. In the general school population, approximately $80 \%$ of students respond to Tier 1 intervention 
alone (Lane, Oakes, \& Menzies, 2014). Based on the high needs of the alternative school population, it is expected that a lower percentage of students in the alternative school setting would respond to Tier 1 supports and a higher percentage would need more intensive interventions and supports. As Simonsen and Sugai (2013) indicated, all three tiers of SW-PBIS can be implemented within the alternative school setting. Such support, however, must go beyond the services provided in the typical school setting to meet the needs of a more impacted population. For this project, investigators focused on supporting the school professionals in systematically developing Tier 1 supports as a means to build a strong foundation for a more comprehensive SW-PBIS approach in the future.

In the present study, 55\% of students responded to SW-PBIS Tier 1 intervention alone (Table 1). Although more targeted and intensive interventions were not systematically implemented for the remaining $45 \%$ of students, the present study sheds light on the individual and school systems-level factors that may be negatively influencing students' responses to Tier 1 intervention. In addition to continued Tier 1 implementation, interventions at the Tier 2 and Tier 3 levels should address the key individual (i.e., hostility, destructive expression of anger, and depression) and environmental (i.e., academic self-concept, attitude toward school, and attitude toward teachers) risk factors identified in "non-responders".

Two of the key individual factors identified in the study were hostility and destructive expression of anger. Therefore, more targeted interventions that address anger may provide the support necessary to help students learn to control their emotions and respond positively to SWPBIS. Over the past decade, research supports the efficacy of anger management interventions has proliferated. Specifically, group-based cognitive therapy that addresses hostility and anger management has been shown to be effective in a variety of settings, including schools, 
community centers, inpatient facilities, residential treatment facilities, and correctional facilities (Feindler \& Engel, 2011; Glick, 2003; Goldstein, Glick, \& Gibbs, 1998; Goldstein, Nensen, Daleflod, \& Kalt, 2004; Nodarse, 1998). Although not studied in the alternative school setting, evidence across settings indicates that group-based anger management interventions may be appropriate in the alternative school setting for students who do not respond to Tier 1 SW-PBIS alone due to hostility and destructive expressions of anger.

In addition to individual factors, the school-level factors identified in non-responders also should be targeted through more intensive interventions. Although continued implementation of SW-PBIS may be enough to help a number of these non-responders to become more responsive, other PBIS interventions, such as CICO, may help students to develop better academic self-concept, attitude to teachers, and overall attitude to school. Research indicates that CICO can help to reduce misbehavior in the classroom (e.g., off-task, escape, aggression, attendance) and overall discipline referrals in a variety of settings, including alternative schools (Andrews, Houchins, \& Varjas, 2017; Hawken, Bundock, Kladis, O’Keefe, \& Barret, 2014; Maggin, Zurheide, Pickett, \& Baille, 2015; Swoszowski, Evanovich, Ennis, \& Jolivette, 2017). By working directly with a school mentor, such as a teacher, to develop goals and monitor progress, students in the alternative setting may develop a sense of accomplishment and belonging, leading to better attitude to teachers and school.

An examination of the different systems (i.e., individual, home, school, and community), showed that only the individual and school systems had significant differences between responders and non-responders to the SW-PBIS intervention. This result indicates that although individuals will have a wide variety of experiences in and perceptions of home and community systems, only the individual and school system predicted intervention response. Although 
schools may have more influence on the individual and school systems compared to home and community systems, schools should not abandon efforts to improve student experiences with and perceptions of the home or community systems. Rather, efforts to improve these systems may provide an indirect link to responsiveness to SW-PBIS. For example, improving parentchild relationships may not directly decrease ORDs or increase tickets earned, but it may improve familial stress. Thus, schools should focus on the individual and school systems for reducing problem behaviors and increasing positive behaviors at school, and use other methods to target the home and community systems.

Future research should not only consider the interventions that may help non-responders to become more responsive to SW-PBIS, but also help to identify which of these interventions are necessary for individual students. Although the current study looked specifically at the implementation of Tier 1 SW-PBIS in the alternative school setting and the ecological factors that affect students' response to intervention, future studies should focus on developing a robust three-tiered model that ensures that all students are getting the specific level of support necessary to be successful.

\section{Limitations}

Several factors limit the generalizability of the current study. Because there was no control school with which to compare results, researchers were unable to draw conclusions regarding SW-PBIS effectiveness in the alternative school setting could not be drawn. In addition, the current study was conducted in only one alternative school with five core teachers, and a total of 42 student participants in the school-wide data analysis. Due to the alternative school's transient student population, the effect may have varied due to student attrition. 
A limitation inherent in the small sample size is the inability to generalize to a broader population. The community from which participating students come is largely Latinx, as reflected in the sample demographics. Further, over $90 \%$ of the students in the school receive a free or reduced-cost lunch, a strong indicator of socioeconomic status that is non-generalizable. In addition, the inclusion of students in special education was low, compared to the typical representation in this population. Investigators and school site professionals believe that this is misleading, as many of the students enrolled in the alternative education program, at this particular site, were receiving significant academic and social/emotional supports, but had not yet been identified as students with special needs. Rather, these students were often inaccurately perceived as "troubled/conduct-disordered" individuals at their home districts, as opposed to students with disabilities who would thrive with more supports. Further, the typical representation of disability in the alternative school population is not clear. Because disability data is not routinely collected and because some students do not always carry their label into alternative programs, the number of students with disabilities attending alternative schools throughout the country is unclear (Lehr \& Lange, 2003). As such, the outcomes and related implications would be generalizable to a high needs population, including individuals with identified disabilities. The results of the study may not generalize to typical youth but are more reflective of those students on the periphery of school engagement.

There is evidence that SW-PBIS was not yet in full implementation. When considering the different structure of the alternative school within the county system and removing those items, however, implementation was at 79\% implementation after the first year. This level of implementation is promising given the full effects of SW-PBIS have taken up to three years in previous studies (Bradshaw, Pas, Debnam, \& Johnson, 2015). 
Finally, the current study included only student self-report measures and did not consider other perspectives (e.g., teachers, staff). Although the measures provided insight into how students perceived the contexts within which they exist, gaining additional information about these contexts from more than one source (e.g., parents, community members) would better inform us which students are most likely to respond to SW-PBIS. Because these data were collected at one point in time, they do not provide developmental information, In future studies, student perceptions should be tracked over time to measure a developmental trajectory and to begin developing an understanding of the critical factors that affect students' lives.

\section{Conclusion}

It is clear that students who enter alternative education programs at the high school level have significant behavioral and mental health needs. Significant differences in risk factors within the individual systems and school systems models, however, make it difficult to differentiate between responders and non-responders to SW-PBIS. Due to the significant differences in risk and protective factors of students in the alternative school setting, the implementation of a "one size fits all" intervention is an ineffective approach. To best serve students in the alternative school setting, it is critical that both educators and researchers continue working to understand which aspects of a school-wide intervention framework may be effective for particular students and further develop more intensive Tier 2 and Tier 3 interventions that meet the needs of students who do not respond to Tier 1 school-wide supports. Continued research in the use of SW-PBIS in the alternative school setting is needed, with specific emphasis in the identification and development of individual and school-based interventions to meet the particular needs of students who experience significant risk factors across all contexts. 
Table 1

Multivariate Analysis of Variance of Individual, School, Home, and Community/Social Systems

\begin{tabular}{|c|c|c|c|c|c|c|}
\hline \multirow[b]{2}{*}{ Variable } & \multicolumn{2}{|c|}{$\begin{array}{c}\text { Responders } \\
(n=22)\end{array}$} & \multicolumn{2}{|c|}{$\begin{array}{l}\text { Non-responders } \\
\quad(n=20)\end{array}$} & \multirow[b]{2}{*}{$F$} & \\
\hline & $M$ & $S D$ & $M$ & $S D$ & & \\
\hline Individual system & & & & & $3.28 *$ & \\
\hline Hostility & 13.59 & 3.16 & 17.05 & 4.34 & & \\
\hline $\begin{array}{l}\text { Destructive } \\
\text { expression }\end{array}$ & 7.73 & 3.03 & 11.85 & 4.42 & $10.13^{*}$ & \\
\hline Depression & 47.90 & 8.17 & 59.60 & 15.44 & $9.25^{*}$ & \\
\hline $\begin{array}{l}\text { Sense of } \\
\text { inadequacy }\end{array}$ & 53.81 & 8.71 & 61.60 & 16.04 & 3.89 & \\
\hline Hope & 21.59 & 5.65 & 19.70 & 6.75 & 0.83 & \\
\hline $\begin{array}{l}\text { Life } \\
\text { satisfaction }\end{array}$ & 20.73 & 4.19 & 19.40 & 8.17 & 0.42 & \\
\hline School system & & & & & $3.20^{*}$ & .04 \\
\hline $\begin{array}{l}\text { Academic } \\
\text { self-concept }\end{array}$ & 26.09 & & 20.40 & 6.73 & $6.38^{*}$ & \\
\hline $\begin{array}{l}\text { Attitude } \\
\text { toward school }\end{array}$ & 55.29 & & 66.00 & 13.01 & $6.36^{*}$ & \\
\hline $\begin{array}{l}\text { Attitude toward } \\
\text { teachers }\end{array}$ & & 11.83 & 66.20 & 13.00 & $7.51 *$ & \\
\hline Home system & & & & & 1.94 & \\
\hline $\begin{array}{l}\text { Family } \\
\text { conflict }\end{array}$ & & 4.75 & 17.50 & 6.68 & 3.92 & \\
\hline $\begin{array}{l}\text { Relations with } \\
\text { parents }\end{array}$ & 42.24 & 12.51 & 40.65 & 14.00 & 0.15 & \\
\hline $\begin{array}{l}\text { Community/social } \\
\text { system }\end{array}$ & & & & & 2.22 & .20 \\
\hline Social stress & 45.52 & 8.59 & 54.45 & 13.33 & 5.98 & \\
\hline $\begin{array}{l}\text { Interpersonal } \\
\text { relations }\end{array}$ & 50.38 & 7.85 & 46.70 & 7.72 & 2.32 & \\
\hline $\begin{array}{l}\text { Community } \\
\text { caring }\end{array}$ & 17.86 & 4.79 & 15.50 & 5.31 & 2.53 & \\
\hline $\begin{array}{l}\text { Norms for } \\
\text { aggression }\end{array}$ & 10.55 & 3.28 & 14.32 & 5.54 & 7.43 & \\
\hline
\end{tabular}


Figure 1. Percentage of critical components in place using the School-wide Evaluation Tool

\section{(SET).}

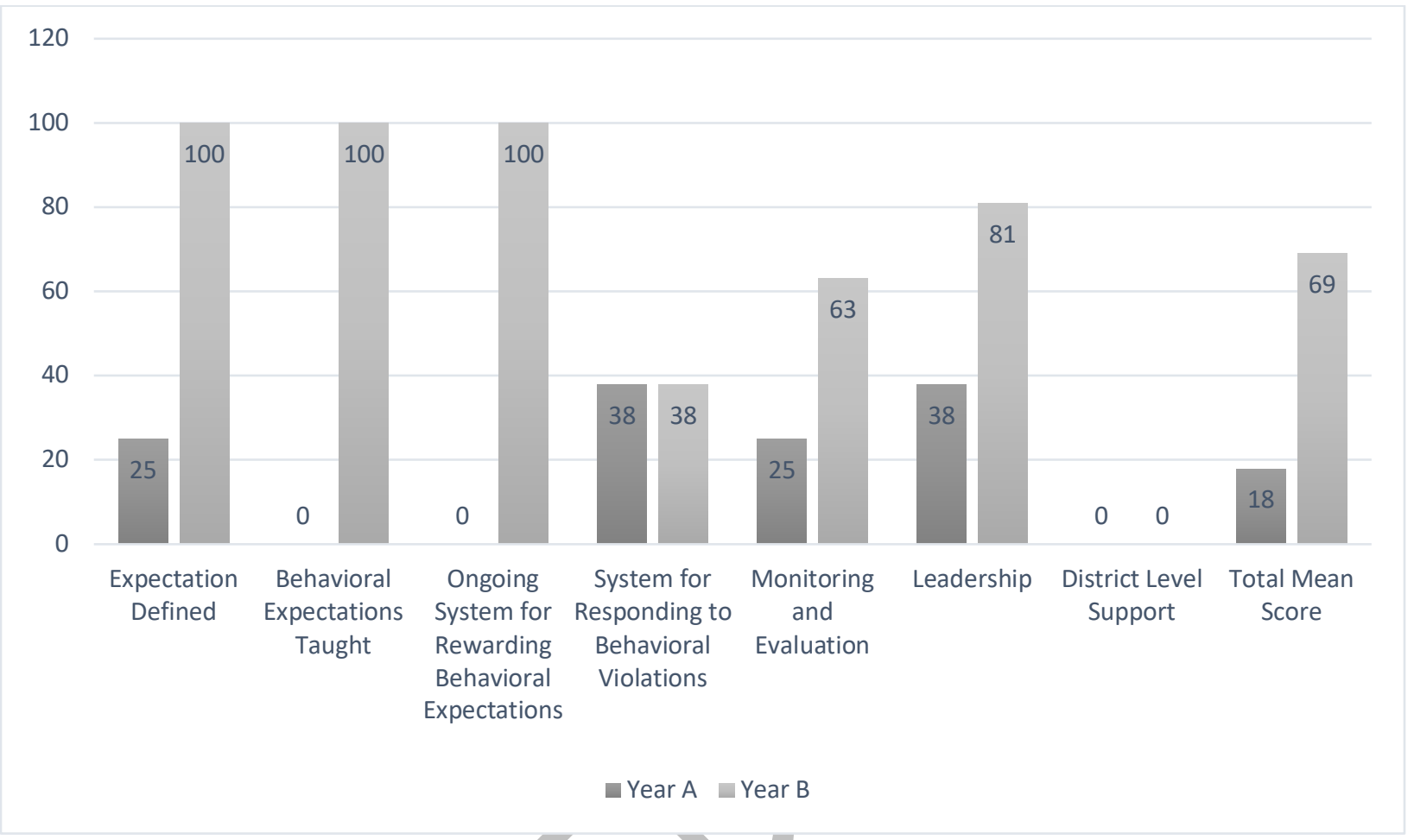




\section{References}

Andrews, W., Houchins, D., \& Varjas, K. (2017). Student-directed check-in/check-out for students in alternative education settings. Teaching Exceptional Children, 49, 380-390.

Bambara, L. M., \& Kern, L. (2005). Individualized supports for students with problem behaviors. New York, NY: The Guilford Press.

Bohanon, H., Fenning, P., Carney, K. L., Missis-Kim, M. J., Anderson-Harriss, S., Moroz, K. B., ... Pigott, T. D. (2006). School-wide application of positive behavior support in an urban high school: A case study. Journal of Positive Behavior Interventions, 8, 131-145. doi:10.1177/10983007060080030201

Boman, P., Curtis, D., Furlong, M. J., \& Smith, D. C. (2006). Cross validation and Rasch analyses of the Multidimensional School Anger Inventory-Revised. Journal of Psychoeducational Assessment, 24, 225-242. doi:10.1177/0734282906288472

Bosworth, K., \& Judkins, M. (2014). Tapping into the power of school climate to prevent bullying: One application of school-wide positive behavior interventions and supports. Theory into Practice, 53, 300-307.

Bradshaw, C. P., Pas, E. T., Debnam, K. J., \& Johnson, S. L. (2015). A focus on implementation of positive behavioral interventions and supports (PBIS) in high schools: Associations with bullying and other indicators of school disorder. School Psychology Review, 44, 480-498. doi:10.17105/spr-15-0105.1

Burke, M. D., Davis, J. L., Hagan-Burke, S., Lee, Y. H., \& Fogarty, M. S. (2014). Using SWPBS expectations as a screening tool to predict behavioral risk in middle school. Journal of Positive Behavior Interventions, 16, 5-17. 
Childs, K. E., Kincaid, D., George, H. P., \& Gage, N. A. (2016). The relationship between school-wide implementation of positive behavior intervention and supports and student discipline outcomes. Journal of Positive Behavior Interventions, 18, 89-99.

Chitiyo, M., May, M. E., \& Chitiyo, G. (2012). An assessment of the evidence-base for schoolwide positive behavior support. Education and Treatment of Children, 35, 1-24. doi:10.1353/etc.2012.0000

Cox, S. M., Davidson, W. S., \& Bynum, T. S. (1995). A meta-analytic assessment of delinquency-related outcomes of alternative education programs. Crime and Delinquency, 41, 219-234. doi:10.1177/0011128795041002004

DeAngelis, K. J., \& Presley, J. B. (2011). Toward a more nuanced understanding of new teacher attrition. Education and Urban Society, 43, 598-626.

Diener, E., Emmons, R. A., Larsen, R. J., \& Griffin, S. (1985). The Satisfaction with Life Scale. Journal of Personality Assessment, 49, 71-75. doi:10.1207/s15327752jpa4901_13

Donnellan, M. B., Trzesniewski, K. H., Robins, R. W., Moffitt, T. E., \& Caspi, A. (2005). Low self-esteem is related to aggression, antisocial behavior, and delinquency. Psychological Science, 16, 328-335.

Farkas, M. S., Simonsen, B., Migdole, S., Donovan, M. E., Clemens, K., \& Cicchese, V. (2012). School-wide positive behavior supports in an alternative school setting: An evaluation of fidelity, outcomes, and social validity of Tier 1 implementation. Journal of Emotional and Behavioral Disorders, 20, 275-288. doi:10.1177/1063426610389615

Feindler, E. A., \& Engel, E. C. (2011). Assessment and intervention for adolescents with anger and aggression difficulties in school settings. Psychology in the Schools, 48, 243-253. 
Foorman, B., York, M., Santi, K., \& Francis, D. J. (2008). Contextual effects on predicting risks for reading difficulties in first and second grade. Reading \& Writing Quarterly, 21, 371-394.

Freeman, J., Simonsen, B., Briere, D. E., \& MacSuga-Gage, A. S. (2013). Pre-service teacher training in classroom management: A review of state accreditation policy and teacher preparation programs. Teacher Education and Special Education, 37, 106-120.

Furlong, M. J., You, S., Smith, D. C., Gonzalez, V., Boman, P., Shimoda, Y., . . Grazioso, M. (2013). An examination of the factorial invariance and refinement of the Multidimensional School Anger Inventory for five Pacific Rim countries. International Journal of School \& Educational Psychology, 1, 2-35. doi:10.1080/21683603.2013.780194

Gagnon, J. C., Rockwell, S. B., \& Scott, T. M. (2008). Positive behavior supports in exclusionary schools: A practical approach with what we know. Focus on Exceptional Children, 41, 1-20.

Gelbar, N. W., Jaffery, R., Stein, R., \& Cýmbala, H. (2015). Case study on the implementation of school-wide positive behavioral interventions and supports in an alternative educational setting. Journal of Education and Psychological Consultation, 25, 287-313.

Glick, B. (2003). Aggression replacement training: A comprehensive intervention for aggressive youth. In B. Schwartz (Ed.), Correctional psychology: Practice, programming, and administration (pp. 14:1-14:20). Kingston, NJ: Civic Research Institute.

Goldstein, A. P., Glick, B., \& Gibbs, J. C. (1998). Aggression replacement training: A comprehensive intervention for aggressive youth (Rev. ed.). Champaign, IL: Research Press. 
Goldstein, A. P., Nensen, R., Daleflod, B., \& Kalt, M. (Eds.). (2004). New perspectives on aggression replacement training: Practice, research, and application. West Sussex, England: John Wiley \& Sons.

Greenwald, A. G., Banaji, M. R., Rudman, L. A., Farnham, S. D., Nosek, B. A., \& Mellott, D. S. (2002). A unified theory of implicit attitudes, stereotypes, self-esteem, and selfconcept. Psychological Review, 109, 3-25.

Hanson, T. L., \& Kim, J. O. (2007). Measuring resilience and youth development: the psychometric properties of the Healthy Kids Survey. (Issues \& Answers Report, REL 2007-No. 034). Washington, DC: U.S. Department of Education, Institute of Education Sciences, National Center for Education Evaluation and Regional Assistance, Regional Educational Laboratory West. Retrieved from http://ies.ed.gov/ncee/edlabs

Harms, A. L. S. (2010). A three-tier model of integrated behavior and learning supports: Linking system-wide implementation to student outcomes. Retrieved from ProQuest Information \& Learning. (AAI3433110).

Hawken, L. S., Bundock, K., Kladis, K., O’Keeffe, B., \& Barrett, C. A. (2014). Systematic review of the check-in, check-out intervention for students at-risk for emotional and behavioral disorders. Education and Treatment of Children, 37, 635-658.

Horner, R., Sugai, G., Smolkowski, K., Todd, A., Nakasato, J., \& Esperanza, J. (2009). A randomized control trial of school-wide positive behavior support in elementary schools. Journal of Positive Behavior Interventions, 11(3), 113-144.

Horner, R. H., Todd, A. W., Lewis-Palmer, T., Irvin, I. K., Sugai, G., \& Boland, J. B. (2004). The school-wide evaluation tool (SET): A research instrument for assessing school-wide 
positive behavior support. Journal of Positive Behavior Interventions, 6, 3-12. doi:10.1177/10983007040060010201

Irvin, L., Tobin, T., Sprague, J. R., Sugai, G., \& Vincent, C. G. (2004). Validity of office discipline referrals measures as indices of school-wide behavioral status and effects of school-wide behavioral interventions. Journal of Positive Behavior Interventions, 6, 3452. doi: $10.1177 / 10983007040060030201$

Jolivette, K., McDaniel, S. C., Sprague, J., Swain-Bradway, J., \& Ennis, R. P. (2012). Embedding the positive behavioral interventions and supports framework into the complex array of practices within alternative education settings: A decision-making process. Assessment for Effective Intervention, 38, 15-29. doi:10.1177/153450841254450

Jolivette, K., Scheuermann, B., \& Parks Ennis, R. (2015). Multi-tiered system of supports within secure residential juvenile facilities. Residential Treatment for Children \& Youth, 32, 254 256.

Kassis, W., Artz, S., \& White, J. (2017). Understanding depression in adolescents: A dynamic prosocial web of risk and protective factors. Child \& Youth Care Forum, 46, 721-743.

Kincaid, D., Dunlap, G., Kern, L., Lane, K. L., Bambara, L. M., Brown, . . Knoster, T. P. (2016). Positive behavior support: A proposal for updating and refining the definition. Journal of Positive Behavior Interventions, 18, 69-73.

Kolaitis, G., Giannakopoulos, G., Tomaras, V., Christogiogos, s., Pomini, V., Layiou-Lignos, E. . Tsiantis, J. (2014). Self-esteem and social adjustment in depressed youths: A randomized trial comparing psychodynamic psychotherapy and family therapy. Psychotherapy and Psychosomatics, 83(4), 249-251. 
Kurdek, L. A., Fine, M. A., \& Sinclair, R. J. (1995). School adjustment in sixth graders: Parenting transitions, family climate, and peer norm effects. Child Development, 66, 430445. doi: $10.2307 / 1131588$

Lane, K. L., Oakes, W. P., \& Menzies, H. M. (2014). Comprehensive, integrated, three-tiered models of prevention: Why does my school—and district—need an integrated approach to meet students' academic, behavioral, and social needs? Preventing School Failure: Alternative Education for Children and Youth, 58, 121-128.

Lam, C., \& McBride-Chang, C. (2007). Resilience in young adulthood: The moderating influences of gender-related personality traits and coping flexibility. Sex Roles, 56(3), $159-172$.

Lassen, S. R., Steele, M. M., \& Sailor, W. (2006). The relationship of school-wide positive behavior support to academic achievement in an urban middle school. Psychology in the Schools, 43, 701-712. doi:10.1002/pits.20177

Leadbeater, B. J. R., \& Way, N. (Eds.). (2007). Urban girls revisited: Building strengths. New York, NY: New York University Press.

Lehr, C. A., \& Lange, C. M. (2003). Alternative schools serving students with and without disabilities: What are the current issues and challenges? Preventing School Failure, $47,59-65$.

Lehr, C., Tan, C., \& Ysseldyke, J. (2009). Alternative schools: A synthesis of state-level policy and research. Remedial and Special Education, 30, 19-32.

doi:10.1177/0741932508315645 
Loeber, R., Farrington, D. P., Stouthamer-Loeber, M., \& White, H. R. (2008). Violence and serious theft: Development and prediction from childhood to adulthood. Mahwah, NJ: Lawrence Erlbaum.

Maggin, D. M., Zurheide, J., Pickett, K. C., \& Baillie, S. J. (2015). A systematic evidence review of the Check-In/Check-Out program for reducing student challenging behaviors. Journal of Positive Behavior Interventions, 17, 197-208.

Michail, S. (2011). Understanding school responses to students' challenging behavior; A review of literature. Improving Schools, 14, 156-171.

Nodarse, M. V. (1998). The effects of "aggression replacement training" on adolescents with an emotional handicap. Dissertations Abstracts International: Section B: The Sciences and Engineering, 58, 6242-6307.

Positive Behavioral Interventions \& Supports. (n.d.). School-wide Positive Behavioral Interventions and Supports. Retrieved from http://www.pbis.org/.

Reynolds, C. R., \& Kamphaus, R. W. (2004). Behavior assessment system for children (2nd ed.). Circle Pines, MN: American Guidance Service.

Rose, L. C., \& Gallup, A. M. (2005). The 48th annual Phi Delta Kappa/Gallup poll of the public's attitudes toward the public schools. Phi Delta Kappan, 98, NP1-NP32.

Ross, S. W., Romer, N., \& Horner, R. H. (2012). Teacher well-being and the implementation of school-wide positive behavior interventions and supports. Journal of Positive Behavior Interventions, 14, 118-128.

Sander, J. B., \& Sharkey, J. D. (2007, March). A review of ecological strategies and programs to address adolescent behavior problems. Poster presented at the National Association of School Psychologists Conference. New York. 
Sameroff, A. J., \& Mackenzie, M. J. (2003). Research strategies for capturing transactional models of development: The limits of the possible. Development and Psychopathology, 15, 613-640. doi:10.1017/S0954579403000312

Schwab, J. R., Johnson, Z. G., Ansley, B. M., Houchins, D. E., \& Varjas, K. (2016). A literature review of alternative school academic interventions for students with and without disabilities. Preventing School Failure, 60, 194-206. doi:10.1080/1045988X.2015.1067874

Simonsen, B., Jeffrey-Pearsall, J., Sugai, G., \& McCurdy, B. (2011). Alternative setting-wide positive behavior support. Behavioral Disorders, 36, 213-224.

Simonsen, B., \& Sugai, G. (2013). PBIS in alternative education settings: Positive support for youth with high-risk behavior. Education \& Treatment of Children, 36, 3-14. doi:10.1353/etc. 2013.0030

Snyder, C. R., Hoza, B., Pelham, W. E., Rapoff, M., Ware, L., Danovsky, M., .. Stahl, K. J. (1997). The development and validation of the Children's Hope Scale. Journal of Pediatric Psychology, 22, 399-421. doi:10.1093/jpepsy/22.3.399

Snyder, T. D., de Brey, C., \& Dillow, S. A. (2016). Digest of education statistics 2015 (NCES 2016-014). Washington, DC: National Center for Education Statistics, Institute of Education Sciences, U.S. Department of Education.

Solomon, B. G., Klein, S. A., Hintze, J. M., Cressey, J. M., \& Peller, S. L. (2012). A metaanalysis of school-wide positive behavior support: An exploratory study using single-case synthesis. Psychology in the Schools, 49, 105-121. doi:10.1002/pits.20625 
Sprague, J. R., Scheuermann, B., Wang, E., Nelson, C. M., Jolivette, K., \& Vincent, C. (2012). Adopting and adapting PBIS for secure juvenile justice settings: Lessons learned. Education and Treatment of Children, 36, 121-134.

Stormshak, E. A., \& Dishion, T. J. (2002). An ecological approach to child and family clinical counseling psychology. Clinical Child and Family Psychology Review, 5, 197-215.

Stronge, J. H., Ward, T. J., \& Grant, L. W. (2011). What makes good teachers good? A crosscase analysis of the connection between teacher effectiveness and student achievement. Journal of Teacher Education, 62, 339-355.

Sugai, G., Hagan-Burke, S., \& Lewis-Palmer, T. (2004). School-wide discipline and instructional classroom management: A systems approach. In C. Darch \& E. Kame’enui (Eds.), Instructional classroom management: A proactive approach to behavior management (2nd ed., pp. 218-248). Upper Saddle River, NJ: Merrill.

Sugai, G., \& Horner, R. H. (2009). Defining and describing school-wide positive behavior support. In W. Sailor, G. Dunlap, G. Sugai, \& R. H. Horner (Eds.) Handbook of positive behavior support (pp. 307-326). New York, NY: Springer.

Sugai, G., Horner, R. H., Dunlap, G., Hieneman, M., Lewis, T. J., Michael Nelson, C. . Ruef, M. (2000). Applying positive behavior support and functional behavior assessments in schools. Journal of Positive Behavior Interventions, 2(3), 131-143.

Sugai, G., Horner, R. H., \& Todd, A. W. (2000). Effective behavior support: Self-assessment survey. Eugene, OR: University of Oregon, Positive Behavioral Interventional and Supports Technical Assistance Center.

Sugai, G., Lewis-Palmer, T., Todd, A. W., \& Horner, R. H. (2001). School-wide Evaluation Tool 2.0. Eugene, OR: Educational and Community Supports, University of Oregon. 
Swoszowski, N. C., Evanovich, L. L., Ennis, R. P., \& Jolivette, K. (2017). Evaluating implementations of check in/check out in alternative education settings: Stakeholder perspectives. Residential Treatment for Children \& Youth, 34, 107-121.

Swoszowski, N. C., McDaniel, S. C., Jolivette, K., \& Melius, P. (2012). The effects of Tier II check-in/check-out including adaptation for non-responders on the off-task behavior of elementary students in a residential treatment facility. Education and Treatment of Children, 36, 63-80.

Theron, L., Liebenberg, L., \& Malindi, M. (2013). When schooling experiences are respectful of children's rights: A pathway to resilience. School Psychology International, 35, 253-265.

Unger, M. (2011). The social ecology of resilience: Addressing contextual and cultural ambiguity of a nascent construct. American Journal of Orthopsychiatry, 81, 1-17.

Wilkerson, K., Afacan, K., Perzigian, A., Justin, W., \& Lequia, J. (2016). Behavior-focused alternative schools: Impact on student outcomes. Behavioral Disorders, 41, 81-94. doi:10.17988/0198-7429-41.2.81 


\section{Author Notes}

Amy-Jane Griffiths, PhD, is an assistant professor in the Attallah College of Educational Studies at Chapman University. Her current research interests include supporting youth and families from underserved communities, specifically youth with emotional and behavioral challenges, and collaborative approaches to academic and mental health assessment and intervention.

Jared T. Izumi, Ed.S., is a doctoral candidate in School Psychology at the University of Missouri. His research interests include early identification and intervention for emotional and behavioral disorders as well as multi-tiered systems of support.

James Alsip, Ed.S., is a school psychologist with Green Dot Public Schools in Los Angeles, California. His current research interests include trauma-informed care, positive behavioral interventions and supports, and academic intervention.

Michael Furlong, PhD, is a Distinguished Professor Emeritus and Research Professor, International Center for School Based Youth Development, University of California Santa Barbara. He is a fellow of the American Psychological Association (Division 16, School) and American Educational Research Association and a member of the Society for Study of School Psychology.

Gale M. Morrison, PhD, is Professor Emeritus of Counseling/Clinical/School Psychology at the University of California, Santa Barbara. Her research interests were risk and resilience, school discipline trajectories of children, school suspension and expulsion practices, and school safety. 